\title{
VALUABLE ENERGY OF BIOCHAR FROM AGRICULTURAL AND FOREST WASTE STREAMS
}

\begin{abstract}
Magdalena DĄBROWSKA, PhD. Department of Agricultural and Forest Engineering, Faculty of Production Engineering, Warsaw University of Life Sciences, Nowoursynowska Street 166, 02-787 Warsaw, Poland, magdalena_dabrowska@sggw.pl (corresponding author)

Milena JAWOREK, Eng. Department of Agricultural and Forest Engineering, Faculty of Production Engineering, Warsaw University of Life Sciences, Nowoursynowska Street 166, 02-787 Warsaw, Poland, milenagodlewska@ gmail.com

Adam ŚWIĘTOCHOWSKI, PhD. Department of Agricultural and Forest Engineering, Faculty of Production Engineering, Warsaw University of Life Sciences, Nowoursynowska Street 166, 02-787 Warsaw, Poland, adam_swietochowski@sggw.pl

Aleksander LISOWSKI, Prof. PhD. Department of Agricultural and Forest Engineering, Faculty of Production Engineering, Warsaw University of Life Sciences, Nowoursynowska Street 166, 02-787 Warsaw, Poland, aleksander_lisowski@sggw.pl

Wastes from forest and agricultural industry are still insufficiently used. One of the ways of their preprocessing is a pyrolysis process. Therefore, the aim of this study was to determine the energetic properties of biochar made of walnut shells, forest wood chips and willow chips. The studies were performed according to standards. The moisture contents of the material, the ash contents, the net and gross calorific values were determined. Low moisture and ash content were found in each of the biochar species. For all tested samples the ash contents were lower than $6 \%$ and for forest wood chips it was $1.5 \%$ only. The way of processing the biomass in the pyrolysis process significantly increased the calorific value of the raw materials. It was found that the net calorific values of the tested materials were high and reached the amount of $26.58 \mathrm{MJ} \cdot \mathrm{kg}^{-1}$ for biochar made of walnut shells, $22.29 \mathrm{MJ} \cdot \mathrm{kg}^{-1}$ for biochar made of forest wood chips and $24.59 \mathrm{MJ} \cdot \mathrm{kg}^{-1}$ for biochar made of willow chips. Due to the good physical properties of biochar produced from waste and biological materials, it was found that these solid fuels can be used for energy purposes.
\end{abstract}

Keywords: biochar, energy properties, waste streams

\section{INTRODUCTION}

The awareness of the impact of human destructive activity on the environment is constantly increasing. It is obvious that the use of fossil fuels in the production of energy threatens the stability of the climate and, consequently, the health of all living organisms. Alternative sources of energy are sought to reduce the greenhouse effect. The intensification of research on renewable energy in Poland and Europe is influenced by European Union legislation on the protection of environment. In order to meet the expectations of domestic companies, research and development concerning the use of biofuels for energy purposes is being pursued. Nowadays, new and upgraded biomass applications are being sought. Research findings during last time aroused a renewed interest in charcoal. One of the most perspective forms of processed biomass is precisely a biochar. Biochar comparing to charcoal can be used as a product itself or as an ingredient within a blended product, with a range of applications not only as fuel but also as an agent for soil improvement. While charcoal is a product of wood treatment, a biochar can be made of different bio-based raw materials.

Biochar is defined as fine-grained, porous and carbon rich solid material produced by the thermal treatment of biomass in an anaerobic environment called pyrolysis (Lehman et al., 2009). Pyrolysis is the basic thermochemical process for converting biomass to a more useful fuel (Demirbas, 1998). In pyrolysis, biomass is converted into liquid, charcoal and non-condensable gasses. Type of biochar obtained in this process is largely dependent on the type of biomass used for biochar production as well as on the process parameters. Due to the biochar stability and high resistance to microbial degradation, biochar can be used in many areas. It has been confirmed that biochar is beneficial for improving soil properties as a natural fertilizer, while the possibility of using it for the production of plastics is still in the research phase (Weisser and Malińska, 2016).

Biochar as a product of thermal decomposition of biomass, has increased energy density compared to raw biomass, is more economical and ecologically more cost effective because its transport, storage and further processing are less expensive. Moreover, biomass has a significantly lower calorific value than most coal (Jensen et al., 2001). This is due to the higher biomass moisture and oxygen contents. Relative to fossil fuels, charcoal contains virtually no sulphur or 
mercury and very little nitrogen and ash. From that reason the conversion of biomass into biochar is a very efficient process and a competitive method for eventually replacing non-renewable fossil fuel resources.

The use of biomass obtained from wastes and side streams products is even better and more ecologically friendly due to its good physical and chemical properties and available amounts of unused raw feedstock. Large quantities of agro and forestry based residues are generated on yearly basis. The major agricultural side streams come from rice husk, coffee husk, maize stalk and husk, sugarcane bagasse, jute sticks, silk cotton pods, groundnut shells (Shri, 2008). Considerable amounts of residues also comes from wood based biomass generated during wood harvesting and processing operations. The side streams products include wood materials, agricultural residues, organic municipal wastes and food processing by-products are considered as one of the main renewable energy sources with a great potential, economic viability and various environmental benefits. There are several studies on agricultural wastes, such as fruit stones and nut shells turning into biochar because of their high mechanical strength and good physical properties. These characteristics can be explained by high lignin contents and low ash amounts in the raw materials (Aygun et al., 2003).

In order to make the best use of biochar, the understanding of its energetic properties is crucial. Therefore, the aim of this study was to determine the energetic properties of biochars made of agricultural and forest residues.

\section{MATERIALS AND METHODS}

Research tests were carried out for three types of biochars made of walnut shells, forest wood chips and willow chips (Fig. 1) obtained from converting biological wastes in the pyrolysis process. The geometric mean values of biochars particles sizes dimensions were $13.32 \mathrm{~mm}, 16.35 \mathrm{~mm}$ and $20.42 \mathrm{~mm}$ for walnut shells, forest wood chips and willow chips, respectively. The particle sizes were determined using a sieve separator with oscillatory motion in the vertical plane. The diversity of biochar shape and size obtained from three types of material did not affect the energy parameters of the fuel, as further samples were ground in the Bosch MKM6003 laboratory mill.

a)

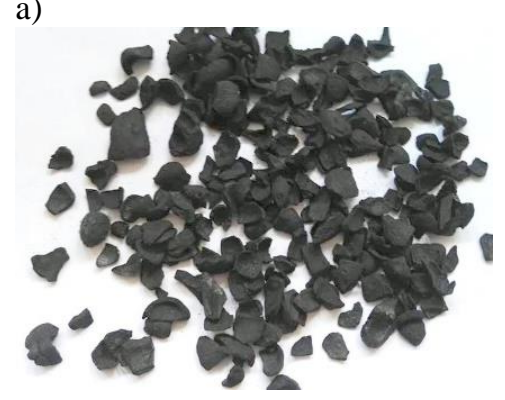

b)

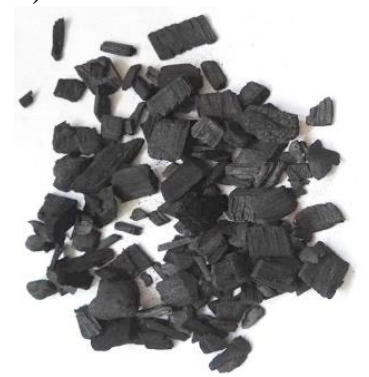

c)

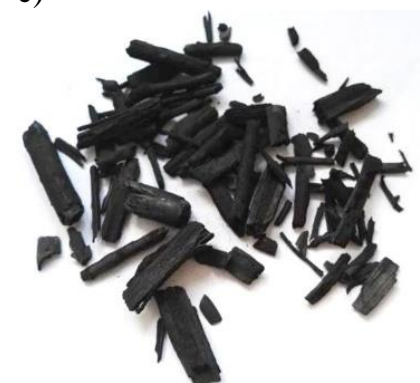

Figure 1 Biochar made of a) walnut shells, b) forest wood chips, c) willow chips

The scope of research included determination of parameters involved with energetic properties of biochar samples: moisture content, calorific value and ash content. All of these tests were performed according to standards. Each trial was repeated five times.

The moisture content was determined by drying-weighting method using RADWAG WPS 600/C scale and SLW 115 laboratory drier. Samples were dried for 24 hours in $105^{\circ} \mathrm{C}$.

The gross calorific value was measured using the standard KL-10 calorimeter according to PN-ISO 1928:2002 standard. The milled sample of $1 \mathrm{~g}$ of material was weighted with accuracy of $0.0001 \mathrm{~g}$ on electronic scale RADWAG WPA 40/160/C/1 and combusted. After that, the net calorific value was calculated taking into account the moisture and hydrogen contents.

The ash content was determined according to standard test method for organic materials (Milne et al., 1992). A clean, dry crucible was weighed, then an appropriate amount of sample (approximately $2.5 \mathrm{~g}$ ) was weighed with an accuracy of 0.0001 in a tared porcelain crucible and after all crucible with sample was reweighed. Measurement was carried out in a muffle furnace at $760^{\circ} \mathrm{C} \pm 20^{\circ} \mathrm{C}$ for several hours and after heting the samples were cooled and reweighed. The ash content was calculated as a ratio of weight of sample remaining and weight of original sample.

\section{RESULTS AND DISCUSSION}

Biochar from biomasses were different in shape depending on the material from which they were obtained. Biochar made of walnut shells was characterized by relatively aligned particles that were a part of the split walnut shells (Fig. 1a) retained their shape after conversion. Biochar made of forest waste streams (Fig. 1b) was composed of differently shaped particles, due to the heterogeneity of the raw material, which was obtained from bark, branches, needles and wood chips. Whereas, biochar made of willow chips was characterized by elongated, slender particles formed after shredding the raw material and particles were differ in shapes and sizes (Fig. 1c).

The moisture content results were similar for each type of biochars and were ranged from $3.7 \%$ to $4.4 \%$. These values were quite low, because the moisture content in biochar should not exceed 15\% (Allaire et al., 2015) but it can be varied depending on the raw material. 
The net calorific values for individual samples were shown in the figure 2. In all cases net calorific values of biomasses were lower than net calorific values of biochar made of these wastes. It proves that the way of processing the biomass in the pyrolysis process significantly increase the calorific value of the raw materials. The highest calorific value $26.58 \mathrm{MJ} \cdot \mathrm{kg}^{-1}$ was determined for biochar made of walnut shells and it was higher by $30 \%$ (by $8 \mathrm{MJ} \mathrm{kg}^{-1}$ ) than calorific value of walnut shells biomass. Similar values were obtained in other research (Zajemska and Musiał, 2013) where calorific value of walnut shells was $18.52 \mathrm{MJ} \cdot \mathrm{kg}^{-1}$. It was found that the net calorific values of raw materials from forest and willow chips wastes were similar and reached the amounts of $16.24 \mathrm{MJ} \cdot \mathrm{kg}^{-1}$ and $16.43 \mathrm{MJ}^{\mathrm{kg}} \mathrm{kg}^{-1}$, respectively. This is consistent with values obtained by another researchers (Niedziółka et al., 2006). Net calorific values of biochar made of forest wood chips and willow chips were also higher by $27 \%$ and $33 \%$, respectively than calorific values of raw wastes materials. These values are comparable to calorific values of coal offered by Polish distributors which are ranged from $24 \mathrm{MJ} \cdot \mathrm{kg}^{-1}$ to $31 \mathrm{MJ} \cdot \mathrm{kg}^{-1}$ with ash contents under 7\%. From that reason biochars made of waste streams may be a good alternative for conventional fuels (http://mervex.pl/).

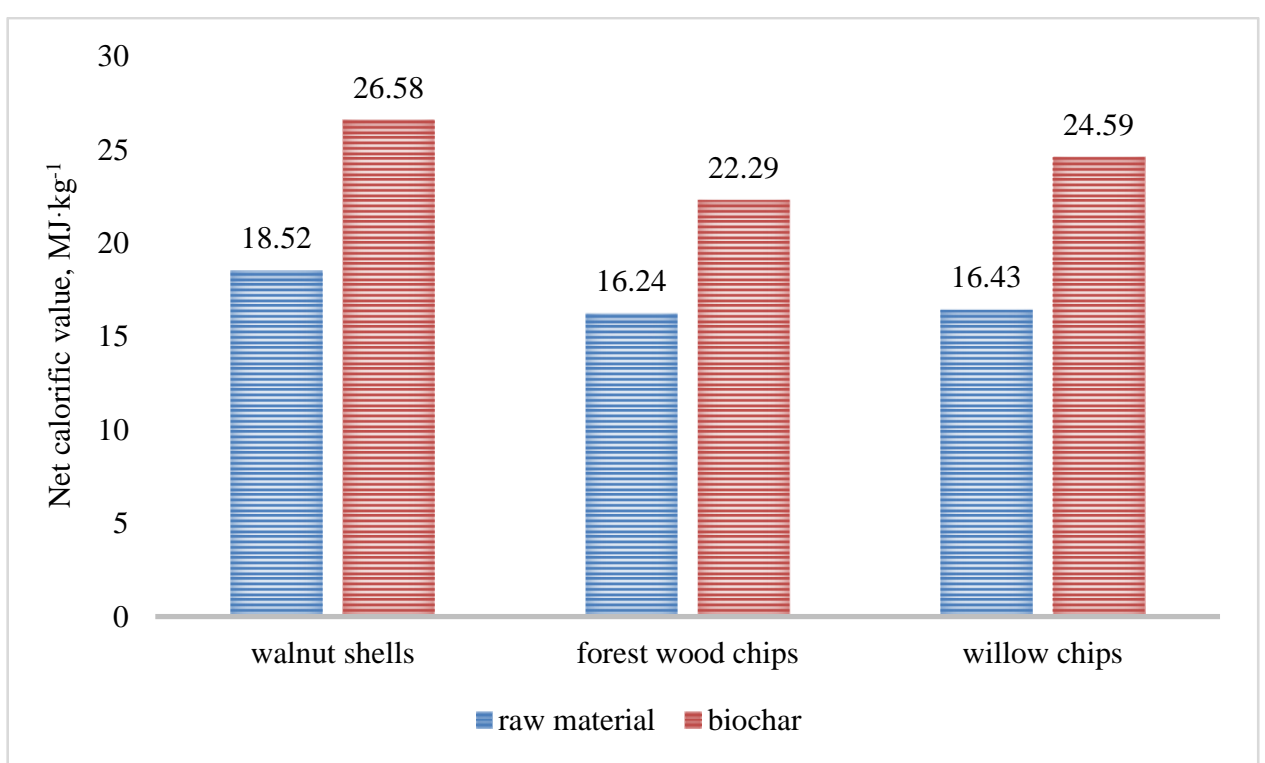

Figure 2. Comparison of net calorific values for raw materials and biochar made of walnut shells, forest wood chips and willow chips

In the energy industry ashes in material are useless and undesirable. Biochar with high ash content is generally less energy-efficient, so it should contain less ash and as much carbon as possible. However, for plant growth ash can be considered as valuable mineral amendment if it does not have hazardous substances and meets environmental standards. Quantity analysis of ash content are significant, because ash has a direct influence on the biochar calorific value decrease and thereby on the quality of formed solid fuel.

The significant differences in colours and shapes in obtained ashes were observed (Fig. 3). It indicates a varied contents of mineral compounds in individual materials, however, it have to be proved by further chemical analysis. Ash remaining after burning the biochar made of walnut shells had a grey colour and its particles were spherical. After burning the biochar made of forest wood chips, the dominant copper colour and the irregular structure of the ash particles were observed. On the other hand, ash obtained after burning the biochar made of willow was beige with elongated particles structure.

a)

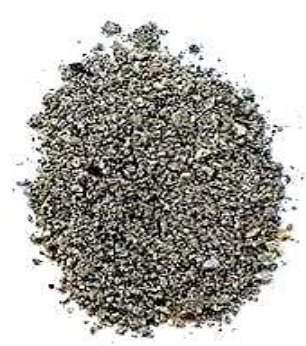

b)

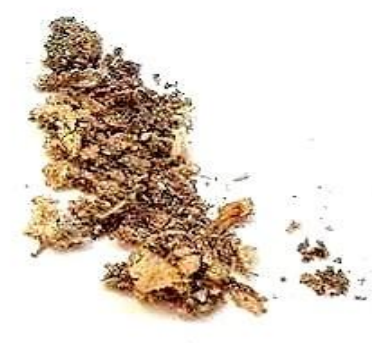

c)

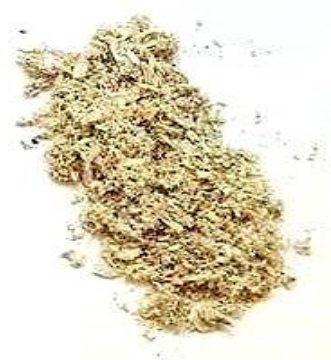

Figure 3. The ashes remaining after burning biochars made of a) walnut shells, b) forest wood chips, c) willow chips 


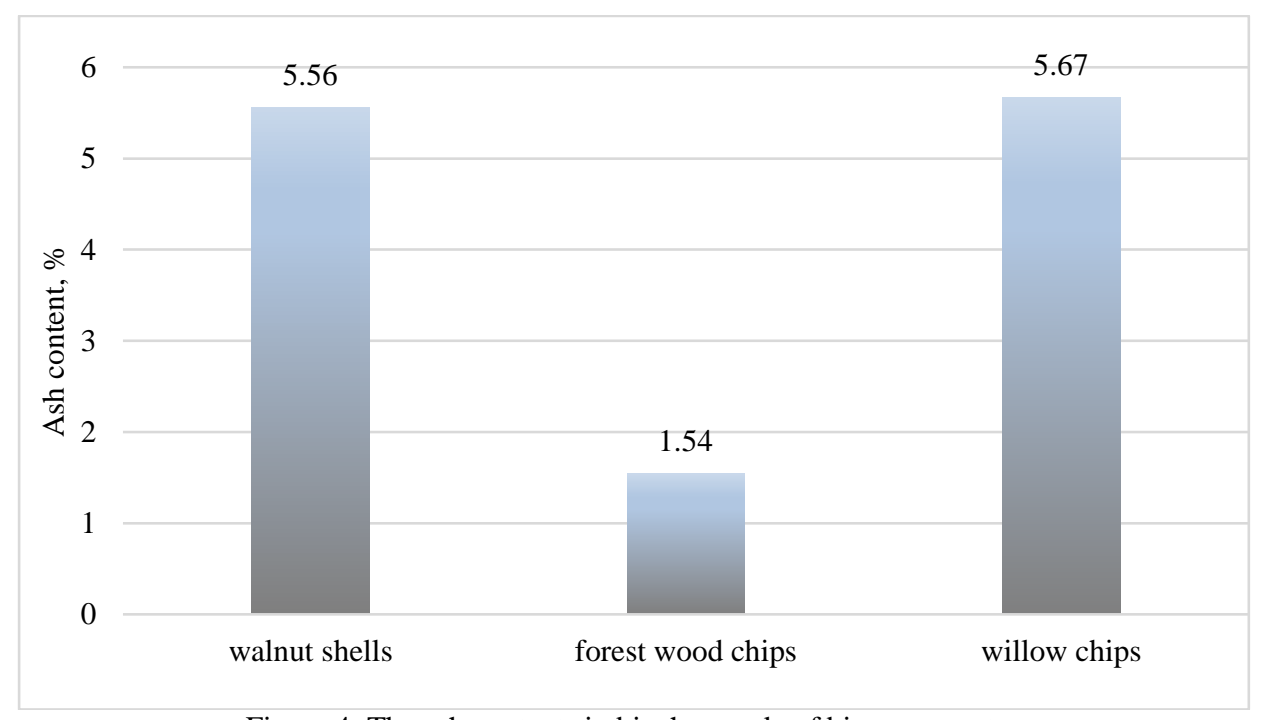

Figure 4. The ash contents in biochar made of biomass wastes

The ash contents of individual samples were shown in the figure 4. It was stated that for each type of tested biochar the ash contents were low, under $6 \%$. Ash content in biochar made of willow chips was the highest $-5.7 \%$. Slightly lower result was obtained for biochar made of walnut shells and it was 5.6\%. The lowest value of ash content $1.5 \%$ was obtained for biochar made of forest wood chips. Analysis of ash content determined in biochar made of other materials showed that obtained values were similar and comparable. In the literature are available data of ash contents for instance in biochar made of olive husks $4.1 \%$ (Demirbas, 2004), coconut shells $2.8 \%$, corncob $4.3 \%$, pine wood $0.7 \%$ (Antal and Gronli, 2003), neem wood residues under 6\% (Sotannde et al., 2010). Because of low ash contents, all of tested materials are desire and valuable as fuels for energy purposes.

\section{CONCLUSIONS}

The experimental results have demonstrated that the biochar derived from waste streams may be used as solid fuels in the domestic or industrial sector due to their good energetic properties.

The way of biomass conversion in the pyrolysis process significantly increased calorific values of the materials. It was found that the net calorific values of the tested materials were high and reached the amount of $26.58 \mathrm{MJ} \mathrm{kg}^{-1}$ for biochar made of walnut shells, $22.29 \mathrm{MJ} \mathrm{kg}^{-1}$ for biochar made of forest wood chips and $24.59 \mathrm{MJ} \mathrm{kg}^{-1}$ for biochar made of willow chips. For all tested samples the ash contents were lower than $6 \%$ and for forest wood chips it was $1.5 \%$ only. Due to the good physical properties of biochar produced from waste and biological materials, it was found that these solid fuels can be used for energy purposes.

\section{REFERENCES}

1. Allaire, S.E., Lange, S.F., Auclair, I.K., Quinche, M., Greffard, L. (The Char Team). 2015. Report: Analyses of biochar properties. CRMR-2015-SA-5. Centre de Recherche sur les Matériaux Renouvelables, Université Laval, Québec, Canada, 59 p. https://doi.org/10.13140/rg.2.1.2789.4241

2. Antal, M.J., Gronli, M. 2003. The art, science, and technology of charcoal production. Journal of Industrial \& Engineering Chemistry Research, Vol. 42, pp. 1619-1640.https://doi.org/10.1021/ie0207919

3. Aygun, A., Yenisoy-Karakas, S., Duman, I. 2003. Production of granular activated carbon from stones and nutshells and evaluation of their physical, chemical and adsorption properties. Microporous and Mesoporous Materials, Vol. 66, pp. 189-195. https://doi.org/10.1016/j.micromeso.2003.08.028

4. Demirbas A. 1998. Yields of oil products from thermochemical biomass conversion processes. Energy Convers Manage, Vol. 39, pp. 685-90. https://doi.org/10.1016/S0196-8904(97)00047-2

5. Demirbas A. 2004. Combustion characteristics of different biomass fuels. Progress in Energy and Combustion Science, Vol. 30, pp. 219-230. https://doi.org/10.1016/j.pecs.2003.10.004

6. Jensen P.A., Sander B., Dam-Johansen K. 2001. Pretreatment of straw for power production by pyrolysis and char wash. Biomass and Bioenergy, Vol. 20, pp. 431-446. https://doi.org/10.1016/S0961-9534(01)00005-8

7. Lehman J., Joseph S. 2009. Biochar for Environmental Management. Science and Technology. Earthscan, London.

8. Mervex Sp. z o.o. 2012. Offer of coal assortments in Poland. Available at http://mervex.pl/ (accesed on 10/11/2017).

9. Milne, T. A.; Chum, H. L.; Agblevor, F. A.; Johnson, D. K. 1992. Standardized Analytical Methods. Biomass and Bioenergy. Proceedings of International Energy Agency Bioenergy Agreement Seminar, Edinburgh, U.K. 2(1-6) pp. 341-366. https://doi.org/10.1016/0961-9534(92)90109-4

10. Niedziółka I., Zuchniarz A. 2006. Energetic analysis of chosen types of plant biomass. Motrol, 8A, pp. $232-237$. 
11. Shri A.M.M. 2008. Biomass charcoal briquetting technology. Shri AMM Murrugappa Chettiar Research Centre Press, TaramaniChennai, India.

12. Sotannde O.A., Oluyege A.O., Abah G.B. 2010. Physical and combustion properties of charcoal briquettes from neem wood residues. Int. Agrophysics, Vol. 24, pp. 189-194.

13. Weisser P., Malińska K., 2016. Biochar as a new material. Biomass Journal, Vol. 3, No. 21, pp. 26-30.

14. Zajemska M., Musiał D. 2013. Energy use of biomass from agriculture in the cofiring process. Problemy Inżynierii Rolniczej. Vol. 4, Iss. 82, pp. 107-118. 